\title{
LOXL2, a copper-dependent monoamine oxidase, activates lung fibroblasts through the TGF-ß/Smad pathway
}

\author{
XIAOHONG WEN $^{1 *}$, YUAN LIU $^{2 *}$, YU BAI $^{1}$, MINGWEI LI $^{3}$, QIANG FU $^{1}$ and YI ZHENG $^{1}$ \\ ${ }^{1}$ Department of Rheumatology and Immunology, Beijing Chaoyang Hospital, Capital Medical University, \\ Beijing 100069; ${ }^{2}$ Department of Rheumatology, First Affiliated Hospital of Baotou Medical College, \\ Inner Mongolia University of Science and Technology, Baotou, Inner Mongolia 014010; ${ }^{3}$ Department of \\ Rheumatology and Immunology, Fu Xing Hospital, Capital Medical University, Beijing 100038, P.R. China
}

Received January 2, 2018; Accepted October 4, 2018

DOI: $10.3892 /$ ijmm.2018.3927

\begin{abstract}
A previous study demonstrated that Lysyl oxidase-like 2 (LOXL2) serves an essential role in matrix remodeling and fibrogenesis, thus indicating its involvement in fibrosis-associated diseases. Our previous studies revealed a novel association between LOXL2 expression and pulmonary fibrosis in mice. However, the exact role and mechanisms of LOXL2 in interstitial lung disease remain poorly understood. The present study aimed to detect LOXL2 expression in mice with bleomycin (BLM)-induced pulmonary fibrosis, and explore the effects of silencing LOXL2 on the proliferation, activation and fibrosis process of mouse lung fibroblasts (MLFs). In addition, the present study investigated the association between LOXL2 and the transforming growth factor- $\beta$ (TGF- $\beta$ )/Smad signaling pathway to identify the mechanism underlying the role of LOXL2 in fibrosis progression. An animal model of pulmonary fibrosis was established by administering an intratracheal injection of $5 \mathrm{mg} / \mathrm{kg}$ BLM to C57BL/6 mice. ELISA and immunohistochemical examination were used to detect the LOXL2 level in the serum, lung homogenate and pulmonary tissues in mice. Pulmonary tissues
\end{abstract}

Correspondence to: Dr Yi Zheng, Department of Rheumatology and Immunology, Beijing Chaoyang Hospital, Capital Medical University, 8 Gongren Tiyuchang Nanlu, Chaoyang, Beijing 100069 , P.R. China

E-mail: zzyy1053@sina.cn

*Contributed equally

Abbreviations: BLM, bleomycin; CCK-8, cell counting kit 8; CT, computed tomography; DMEM, Dulbecco's modified Eagle's medium; dsDNA, double-strand DNA; H\&E, hematoxylin and eosin; LOX, Lysyl oxidase; MLFs, mouse lung fibroblasts; PCR, polymerase chain reaction; PE, phycoerythrin; PFUs, plaque-forming units; siRNA, short interfering RNA; SMA, smooth muscle actin; TGF- $\beta$, transforming growth factor- $\beta$

Key words: pulmonary fibrosis, lysyl oxidase 2, small interfering RNA, transforming growth factor- $\beta /$ Smad of mice were extracted to culture primary MLFs, and a LOXL2 small interfering RNA adenovirus vector was established to silence LOXL2 in MLFs. Cell proliferation was detected using the cell counting kit- 8 assay. Reverse transcription-quantitative polymerase chain reaction and western blotting were used to measure the expression of LOXL2, TGF- $\beta 1, \operatorname{Smad} 2 / 3$, phosphorylated (p)Smad2/3, Smad4, and Smad7 and Snail in cells. Interleukin-6 (IL-6) and type 1 collagen $\alpha 1$ (COL1A1) in the supernatant of cells were analyzed by ELISA. It was demonstrated that LOXL2 expression was significantly increased in serum, lung homogenate and pulmonary tissues of mice with BLM-induced pulmonary fibrosis compared with control mice. Furthermore, silencing LOXL2 significantly decreased MLF proliferation, and the levels of IL- 6 and COL1A1 in the supernatant of cells. Furthermore, silencing LOXL2 inhibited the expression of pSmad2/3, Smad4 and Snail, while it promoted Smad7 expression. The present data provides a comprehensive analysis of the LOXL2 in pulmonary fibrosis and indicates prominent roles for LOXL2 in fibrogenesis via regulation of the TGF- $\beta /$ Smad signaling pathway.

\section{Introduction}

Interstitial lung disease represents a group of diseases involving diffuse lung parenchyma injury, alveolar inflammation and interstitial fibrosis as the basic pathological lesions. These diseases are characterized by a gradual deterioration of pulmonary functions in the majority of patients, eventually developing into extensive pulmonary fibrosis leading to respiratory failure (1). The pathogenesis involves a variety of cells, including alveolar epithelial cells and lung fibroblasts, inflammatory cytokines, as well as transforming growth factor (TGF)- $\beta 1$ signal transduction (2-5). The incidence rate per 100,000 people has been reported to range between 10 and 60 cases in the United States and appears to increase with age, but the pathogenesis remains elusive (6,7). Due to the varied clinical manifestations and pathological types, clinical treatment is unsatisfactory. Once extensive fibrosis occurs, the treatment options are further limited, increasing the risk of mortality $(8,9)$. Therefore, the pathogenesis underlying and potential therapeutic targets of pulmonary fibrosis require further investigation. 
Lysyl oxidase (LOX) is a copper-dependent amine oxidase that consists of four members (LOX-like 1-4) located in the extracellular space and nucleus, among which LOX-like 2 (LOXL2) serves an essential role in matrix remodeling and fibrogenesis (10-12). A previous study demonstrated that LOXL2 is involved in epithelial-mesenchymal transition, extracellular matrix deposition, and occurrence and progression of fibrosis-associated diseases (13). Barry-Hamilton et al (14) reported that the expression of LOXL2 elevated significantly in pulmonary tissues of mice with pulmonary fibrosis, whereas the fibrosis process was inhibited by LOXL2-specific antibody treatment. Another study demonstrated that LOXL2 was highly expressed in the pulmonary fibroblasts of patients with idiopathic pulmonary fibrosis, and essential in the transition of fibroblasts to myofibroblasts (15). Although LOXL2 is involved in the occurrence and progression of pulmonary fibrosis, its specific roles and mechanisms require further investigation.

A large amount of extracellular matrix is produced by fibroblasts and the transition of fibroblasts to myofibroblasts is one of the primary characteristics of pulmonary fibrosis (16). The TGF- $\beta 1$ signaling pathway has been implicated in the development of pulmonary fibrosis, with the classical TGF- $\beta 1 / \mathrm{Smad}$ being one of the most important pathways (17). TGF- $\beta 1$ acts on target cells through the transmembrane receptors, leading to the phosphorylation of Smad2 and Smad3. Phosphorylated Smad2/3 binds to Smad4 to enter the nucleus. Following nuclear translocation, the Smad protein compound interacts with transcription factor Snail to regulate the transcription of fibrosis-associated genes in the downstream. Inhibitory Smads (Smad6 and Smad7) promote the degradation of TGF- $\beta 1$ and inhibit the activation of the TGF- $\beta 1$ signaling pathway $(18,19)$. A previous study revealed that following the knockout of LOX in C57BL/6 mice, the expression of TGF in the bronchoalveolar lavage fluid (BALF) is downregulated and the proportion of pSmad2/3-positive cells in the pulmonary tissues decreases, suggesting an association between LOX and the TGF- $\beta$ signaling pathway (18). Although LOXL2 is implicated in the occurrence and development of pulmonary fibrosis, and LOX may act through the TGF- $\beta$ signaling pathway, studies on the specific effects of LOXL2 on the proliferation and fibrosis progression of lung fibroblasts of bleomycin (BLM)-induced pulmonary fibrosis in mice, as well as the involvement of LOXL2 in the progression of pulmonary fibrosis through the TGF- $\beta 1 /$ Smad signaling pathway, are limited $(20,21)$.

Therefore, mice models with BLM-induced pulmonary fibrosis were used in the present study, and the expression of LOXL2 in serum, lung homogenate and pulmonary tissues was observed. Then, the pulmonary tissues of mice were extracted to culture primary MLFs, and the cells were transfected using LOXL2 short interfering RNA (siRNA). The effects of LOXL2 silencing on the proliferative ability, and the expression of inflammatory factors interleukin (IL)-6 and extracellular matrix type 1 collagen $\alpha 1$ (COL1A1) involved in fibrosis progression were determined in vitro. In addition, the effects of LOXL2 siRNA on the expression of key factors in the TGF- $\beta 1$ signaling pathway were also noted. Further investigations were performed to examine the effect of LOXL2 on the occurrence of pulmonary fibrosis and its regulatory mechanism in the TGF- $\beta$ /Smad signaling pathway, providing experimental evidence for the identification of potential therapeutic targets of pulmonary fibrosis.

\section{Materials and methods}

Major reagents. C57BL/6 mice were purchased from Beijing Vital River Laboratory Animal Technology Co., Ltd. (Beijing, China), and 293 cells and the adenovirus vector PGMAV-S1 were provided by Lemo Biotechnology (Hebei, China). BLM was purchased from Nippon Kayaku Co., Ltd. (Tokyo, Japan). The RNA simple Total RNA kit (cat. no. DP419) was purchased from Tiangen Biotech Co., Ltd. (Beijing, China). The Prime Script $^{\mathrm{TM}}$ RT reagent kit, SYBR ${ }^{\circledR}$ Prime Script plus RT-PCR kit, DNA ligase, Taq DNA polymerase and restriction endonucleases were purchased from Takara Bio, Inc. (Otsu, Japan). Taq polymerase was purchased from New England Bio Labs, Inc. (Ipswich, MA, USA). The QIA prep Spin Mini prep kit was purchased from Qiagen GmbH (Hilden, Germany). The DNA Gel Extraction kit was purchased from Generay Biotech Co., Ltd. (Shanghai, China). The NucleoSpin ${ }^{\circledR} 96$ Plasmid Core kit was purchased from Macherey-Nagel GmbH (Düren, Germany). Lipofectamine ${ }^{\circledR} 2000$ was purchased from Thermo Fisher Scientific,Inc.(Invitrogen; Waltham,MA,USA).LOXL2 (cat. no. ab96233), TGF- $\beta 1$ (cat. no. ab92486), phosphorylated (p)Smad2/3 (cat. no. ab63399) and Smad4 (cat. no. ab40759) rabbit anti-mouse primary antibodies were purchased from Abcam (Cambridge, UK). Smad7 (cat. no. sc-365846), Snail (cat. no. sc-271977) mouse monoclonal antibodies, and the mouse $\mathrm{IgG \kappa}$ binding protein (cat. no. sc-516102) and goat anti-rabbit IgG (cat. no. sc-2030) HRP-conjugated secondary antibodies were purchased from Santa Cruz Biotechnology, Inc. (Dallas, TX, USA). The ProteoPrep ${ }^{\circledR}$ Total Extraction Sample and Bicinchoninic Acid kits was purchased from Sigma-Aldrich; Merck KGaA (Darmstadt, Germany). The LOXL2 ELISA kit (cat. no. A95552Mu02) was purchased from Shanghai Wuhao Trade Co., Ltd. (Shanghai, China), the IL-6 ELISA kit (cat. no. M6000B) from R\&D Systems, Inc. (Minneapolis, MN, USA) and the COL1A1 ELISA kit (cat. no. SEA350Mu) from Wuhan USCN Business Co., Ltd. (Wuhan, China). Primer synthesis was performed by Sangon Biotech Co., Ltd. (Shanghai, China). The Hematoxylin Staining kit and Masson Tri-color Staining kit were purchased from Beijing Solarbio Science \& Technology Co., Ltd. (Beijing, China). Plasmid sequencing was performed by Thermo Fisher Scientific, Inc. (Invitrogen).

Construction of LOXL2 siRNA adenovirus vectors. The present study was approved by the Experimental Animal Welfare Committee of Capital Medical University (Beijing, China; approval no. AEEI-2016-005). Two siRNAs and one scramble siRNA (negative control) were designed for cDNA sequence of LOXL2 gene (serial no. NM_033325.2), as shown in Table I.

Four single-strand DNAs were synthesized, which formed double-strand DNA (dsDNA) via annealing. The dsDNA was bound to linearize adenovirus vector PGMAV-S1 following double-enzyme digestion by BamHI and HindIII. The ligations were transformed into Escherichia coli DH5 $\alpha$, and positive clones were selected. Plasmids were extracted and gene sequencing was performed to identify the recombinants. 
Table I. siRNA oligo sequences.

\begin{tabular}{|c|c|c|}
\hline siRNA & & OligoDNA sequence $\left(5^{\prime}-3^{\prime}\right)$ \\
\hline LOXL2 siRNA1 & $\begin{array}{l}\text { Forward } \\
\text { Reverse }\end{array}$ & $\begin{array}{l}\text { gatccGCCAGAAGAGGAAGCACAATGTTCAAGAGACATTGT } \\
\text { GCTTCCTCTTCTGGCTTTTTTa } \\
\text { agcttAAAAAAGCCAGAAGAGGAAGCACAATGTC } \\
\text { TCTTGAACATTGTGCTTCCTCTTCTGGCg }\end{array}$ \\
\hline LOXL2 siRNA2 & $\begin{array}{l}\text { Forward } \\
\text { Reverse }\end{array}$ & $\begin{array}{l}\text { gatccGGAAGCAGATCTGCAACAAACTTCAAGAGAGTTTGTTGC } \\
\text { AGATCTGCTTCCTTTTTTa } \\
\text { agcttAAAAAAGGAAGCAGATCTGCAACAAACTCTCTTGA } \\
\text { AGTTTGTTGCAGATCTGCTTCCg }\end{array}$ \\
\hline Control siRNA & $\begin{array}{l}\text { Forward } \\
\text { Reverse }\end{array}$ & $\begin{array}{l}\text { gatccGGTACTGGCATGGAAATATCTTTCAAGAGAAGATATTTCC } \\
\text { ATGCCAGTACCTTTTTTa } \\
\text { agcttAAAAAAGGTACTGGCATGGAAATATCTTCTCTTGAAAGAT } \\
\text { ATTTCCATGCCAGTACCg }\end{array}$ \\
\hline
\end{tabular}

LOXL2, Lysyl oxidase-like 2; siRNA, small interfering RNA.

A large number of recombinant plasmids were prepared, and 293 cells were then transfected with siRNA through mediation by liposomes using Lipofectamine 2000. Following the purification and determination of the virus titer, the recombinant adenovirus was packaged and stored at $-80^{\circ} \mathrm{C}$ for subsequent use. Eventually, a total of $1.0 \times 10^{10}$ plaque-forming units (PFUs)/ml LOXL2 siRNA adenovirus vectors together with $1.1 \times 10^{9} \mathrm{PFUs} / \mathrm{ml}$ negative control siRNA were harvested.

Construction and identification of animal models with pulmonary fibrosis. A total of $16 \mathrm{C} 57 \mathrm{BL} / 6$ male mice, aged 7-8 weeks and weighing 17-20 g, were pre-fed a normal diet with standard feed in a new environment for 1 week and kept in an environment of $20-22^{\circ} \mathrm{C}$ with $50-60 \%$ relative humidity. Furthermore, the mice were housed in a 12-h light/12-h dark cycle, the background noise was kept $<60$ decibels, and the ammonia concentration was kept $<20 \mathrm{ppm}$. The mice had free access to fresh and clean water as well as adequate feedstuff with balanced nutrition. They were randomly divided into control (saline injection) and BLM groups (intratracheal injection was performed once at a dose of BLM $5.0 \mathrm{mg} / \mathrm{kg}$ ), with eight mice in each group. Pulmonary fibrosis models were identified by imaging examination and pathological morphology 14 days after completing BLM treatment. The serum of mice was used to prepare lung homogenate following the successful construction of the models for subsequent experiments. For imaging evaluation, mice anesthetized with a $5 \% 300 \mathrm{mg} / \mathrm{kg}$ chloral hydrate intraperitoneal injection were placed in the fixed device of the computed tomography (CT) machine (Siemens AG, Munich, Germany) in a supine position. The CT machine was set to an appropriate position to perform the spiral scan of the whole lung with the parameters including layer thickness of $0.625 \mathrm{~mm}, 120 \mathrm{kV}$ and $100 \mathrm{~mA}$. The scanning conditions and parameters were consistent in the two groups, and Mimics 15.0 software (Materialise NV, Leuven, Belgium) was used for analysis. For pathological morphology analysis, a section of the pulmonary tissues was fixed with $4 \%$ paraformaldehyde overnight at room temperature, dehydrated in varying concentrations of ethanol, paraffin-embedded, and sliced into 3-5-mm thick sections. The tissues were then stained with hematoxylin and eosin (H\&E), and Masson's trichrome staining. For H\&E staining, tissue slices were stained with $90 \%$ hematoxylin dye solution for 10-15 min, allowed to differentiate for $30 \mathrm{sec}$ and then stained with $0.5 \%$ eosin dye solution for $2 \mathrm{~min}$. For Masson's staining, tissue slices were stained with $98 \%$ Weigert hematoxylin for 10 min, differentiated with $1 \%$ phospho molybdate solution for $10 \mathrm{sec}$ and returned to blue using $1 \%$ Masson blue liquor for $5 \mathrm{~min}$. Slides were then dyed with $1 \%$ Li Chunhong's magenta for $5 \mathrm{~min}$ followed by $2 \%$ aniline blue dyeing solution for 1-2 min. All of the aforementioned staining procedures were performed at room temperature. Subsequently, pulmonary tissue inflammation, morphological changes and fibrosis degree were observed with an optical microscope using x20 magnification (Olympus BX43; Olympus Corporation, Tokyo, Japan).

Culture and identification of primary MLFs. Pulmonary tissues were selected from the control and BLM model groups. The pleura and blood vessels were removed, and the tissues were cut into tissue blocks of the size of $\sim 1 \mathrm{~mm}^{3}$. A $25-\mathrm{cm}^{2}$ culture flask was coated with Dulbecco's modified Eagle's medium (DMEM) (Invitrogen; Thermo Fisher Scientific, Inc.) containing 10\% fetal bovine serum (HyClone; GE Healthcare Life Sciences, Logan, UT, USA), and the $1-\mathrm{mm}^{3}$ tissue blocks were attached to the bottom of the culture flask evenly. Then, $5 \mathrm{ml}$ of DMEM/F-12 medium containing $10 \%$ fetal bovine serum was added to cover the tissue blocks following adhesion in $5 \% \mathrm{CO}_{2}$ at $37^{\circ} \mathrm{C}$ for $12 \mathrm{~h}$. Once the cells reached the fusion state, $0.25 \%$ trypsin was added, and the cells were passaged at a ratio of 1:3 until the third generation. The cells were cultured until $90 \%$ confluent, fixed with $4 \%$ paraformaldehyde for $30 \mathrm{~min}$, incubated with $0.2 \%$ Triton X-100 for 5 min and blocked 5\% bovine serum albumin (Wuhan Boster Biological Technology, Ltd., Wuhan, China) for 30 min (all performed at room temperature). Cells were then incubated 
with the PBS-diluted $\alpha$-smooth muscle actin ( $\alpha$-SMA) mouse monoclonal antibody (cat. no. A5228; 1:300; Sigma-Aldrich; Merck $\mathrm{KGaA}$ ) at $37^{\circ} \mathrm{C}$ for $1 \mathrm{~h}$, followed by incubation with the goat anti-rabbit phycoerythrin-conjugated secondary antibody (cat. no. 11828681001; 1:1,000; Sigma-Aldrich; Merck KGaA) for $1 \mathrm{~h}$ at room temperature. Then, the cells were observed under an inverted fluorescence microscope (Olympus IX71; Olympus Corporation) at magnifications x200 and x400 to identify MLFs.

Infection of MLFs with adenovirus siRNA. The MLF fusion degree in the control and BLM groups was 60-80\%. Plating was performed using a 6-well plate at the inoculation density of $1 \times 10^{5}$ cells $/ \mathrm{ml}$. MLFs of the BLM model group were divided into four groups: BLM, control siRNA, LOXL2 siRNA1, and LOXL2 siRNA2. The cells in the latter three groups were transfected with control siRNA, LOXL2 siRNA1, and LOXL2 siRNA2, respectively, with a multiplicity of infection of 100 for $2 \mathrm{~h}$ at $37^{\circ} \mathrm{C}$. The cells were continuously cultured for $48 \mathrm{~h}$ after transferring them to the fresh culture medium (DMEM). A FACScan system (BD Biosciences, San Jose, CA, USA) was used in flow cytometry to observe the infection efficiency. The infection efficiency was $>70 \%$. The cells and supernatant were collected.

Detection of cell proliferation using the Cell Counting kit- 8 assay. The cells were counted and inoculated into 96-well plates with $100 \mu \mathrm{l}$ of cell suspension/well $\left(1 \times 10^{3}\right.$ cells/well). Each sample was repeated in triplicate. The cells were precultured in an inoculator containing $5 \% \mathrm{CO}_{2}$ at $37^{\circ} \mathrm{C}$ for $24 \mathrm{~h}$, and $10 \mu \mathrm{l}$ of CCK- 8 solution was added to each well, followed by incubation for 1-4 h. The absorbance values at $450 \mathrm{~nm}$ were measured using a microplate reader. Three biological replicates were performed and each experiment was repeated three times.

Detection of gene expression in MLFs using reverse transcription-quantitative polymerase chain reaction ( $R T-q P C R)$. Total RNA was extracted using the RNAsimple Total RNA kit according to the manufacturer's protocol following transfection of MLFs for $48 \mathrm{~h}$. Then, it was reverse transcribed to synthesize cDNA using the PrimeScript RT reagent kit using the following temperature protocol: $37^{\circ} \mathrm{C}$ for $15 \mathrm{~min} ; 85^{\circ} \mathrm{C}$ for $5 \mathrm{sec}$; and $4^{\circ} \mathrm{C}$ for $5 \mathrm{~min}$. The mRNA level was amplified and detected using SYBR PrimeScript plus RT-PCR kit according to the manufacturer's protocol. The primers were designed and synthesized (Table II). The thermocycling conditions for qPCR were as follows: $95^{\circ} \mathrm{C}$ for $30 \mathrm{sec} ; 60^{\circ} \mathrm{C}$ for $30 \mathrm{sec}$; and $72^{\circ} \mathrm{C}$ for $30 \mathrm{sec}$, with a total of 40 cycles. RT-qPCR was performed using ABI Prism 7500 (Applied Biosystems; Thermo Fisher Scientific, Inc.). GAPDH was used as the internal reference and the relative expression of genes was calculated using the $2^{-\Delta \Delta \mathrm{Cq}}$ method (22). The experiments were performed at least three times.

Detection of protein expression in MLFs using western blotting. Protein was extracted from MLFs by pyrolysis using the ProteoPrep Total Extraction Sample kit and detected using the Bicinchoninic Acid kit according to the manufacturers' protocols. The protein samples were adjusted to the same
Table II. Primers used for polymerase chain reaction.

\begin{tabular}{ll}
\hline Gene & \multicolumn{1}{c}{ Sequences $\left(5^{\prime}-3^{\prime}\right)$} \\
\hline LOXL2 & F: ATGACAGCAGGAGCGTGAGGT \\
& R: GGTTTAGAGCAGCAGAGAAGGGTAAG \\
TGF- $\beta 1$ & F: AGCAACAATTCCTGGCGTTACCTT \\
& R: CCTGTATTCCGTCTCCTTGGTTCAG \\
Smad2 & F: GCTTAGTCCTGTGAGAGTTCCTGTTG \\
& R: ACTGACAACCAAGGCGTGATGAAG \\
Smad3 & F: AGAACACCGATTCCACTCAACTAAGG \\
& R: AAGCCACCAGAACAGAAGCCATC \\
Smad4 & F: TCAGGTGTGGCTCAGTGCTTGA \\
& R: GCCGACTCCTCCATACAGAACCA \\
Smad7 & F: CGGACAGCTCAATTCGGACAACA \\
& R: CAGTGTGGCGGACTTGATGAAGAT \\
Snai1 & F: ACCTGGTTCCTGCTTGGCTCTC \\
& R: AGTGGGTTGGCTTTAGTTCTATGGC \\
GAPDH & F: AGAAGGTGGTGAAGCAGGCATCT \\
& R: CGGCATCGAAGGTGGAAGAGTG \\
\hline
\end{tabular}

LOXL2, Lysyl oxidase-like 2 ; TGF- $\beta 1$, tumor growth factor- $\beta 1$; $\mathrm{F}$, forward; $\mathrm{R}$, reverse.

concentration. Equal amounts of total protein $(50 \mu \mathrm{g} / 10 \mu \mathrm{l} / \mathrm{lane})$ were separated using on $10 \%$ SDS-PAGE gels and then electro transferred to a nitrocellulose membrane. Next, membranes were blocked with 5\% skimmed milk powder for $1 \mathrm{~h}$ at room temperature. The proteins were incubated with the primary antibodies against rabbit anti-mouse LOXL2 $(1: 2,000)$, TGF- $\beta 1$ (1:500), Smad2/3 (1:500), Phospho-Smad2/3 (1:500), Smad4 (1:500), Smad7 (1:500), Snail (1:500) and GAPDH $(1: 5,000)$ at $4^{\circ} \mathrm{C}$ overnight. Then, the membranes were incubated with the horseradish peroxidase-conjugated goat anti-rabbit immunoglobulin $\mathrm{G}(1: 5,000)$ for $1 \mathrm{~h}$ at room temperature, followed by exposure and development using Immobilon ECL Ultra Western HRP substrate (Merck KGaA).

Detecting the expression of LOXL2 in serum and lung homogenate, and the IL-6 and COL1A1 levels in cell supernatant using ELISA. The serum of mice was collected and lung homogenate was prepared $(0.5 \mathrm{~g}$ tissues were mixed with $5 \mathrm{ml}$ of precooled PBS). The tissues were thoroughly ground in a glass homogenizer on ice. After a freeze-thaw cycle (freezing at $-20^{\circ} \mathrm{C}$ and then dissolving at room temperature three times), the cell membrane was cracked and centrifuged at $1,006 \mathrm{x} \mathrm{g}$ for $5 \mathrm{~min}$ at $4^{\circ} \mathrm{C}$ followed by the removal of the supernatant. The supernatant was retained for the ELISA cell experiments. ELISA was performed according to the protocols of the LOXL2, IL-6 and COL1A1 ELISA kits.

Detection of the expression of LOXL2 in pulmonary tissues in mice using immunohistochemical analysis. The paraffin-embedded slices were baked at $67^{\circ} \mathrm{C}$, dewaxed in xylene, and then rehydrated in a descending ethanol series. The slices were washed with PBS. Antigen retrieval was performed 
by boiling at $95^{\circ} \mathrm{C}$. The activation of endogenous peroxidase was blocked by incubation of slices in $50 \mu \mathrm{l}$ of peroxidase at room temperature for $10 \mathrm{~min}$. Following washing with PBS, the slices were blocked with goat serum (Wuhan Boster Biological Technology, Ltd.) at room temperature for $10 \mathrm{~min}$. Then, the serum was removed, and $50 \mu$ l of primary antibody against LOXL2 (1:100) was added and incubated overnight at $4^{\circ} \mathrm{C}$. Following washing with PBS, slices were incubated with 1-2 drops of goat anti-rabbit IgG secondary antibody $(1: 5,000)$ at room temperature for $10 \mathrm{~min}$. Then, streptavidin biotin-peroxidase solution was added for $30 \mathrm{~min}$ at room temperature, followed by the addition of $100 \mu \mathrm{l}$ of 3,3'-diaminobenzidine coloring solution for 3-10 min. Subsequently, $90 \%$ hematoxylin re-staining was performed for $5 \mathrm{~min}$, followed by gradient dehydration ( $70 \%$ ethanol, $1 \mathrm{~min} ; 80 \%$ ethanol, $1 \mathrm{~min} ; 95 \%$ ethanol, $2 \mathrm{~min}$ ), $0.1 \% \mathrm{HCl}$ differentiation (3 min), $0.1 \%$ ammonia treatment (1-2 min) and drying, which were all performed at room temperature. The slices were observed with an optical microscope at x20 magnification (Olympus BX43; Olympus Corporation).

Statistical analysis. The experimental data were analyzed using the SPSS 17.0 statistical software (SPSS, Inc., Chicago, IL, USA). The results are presented as the mean \pm standard deviation. Two groups were compared using the independent-samples t-test, while multiple groups were compared using one-way analysis of variance followed by the Fisher's least significant difference or Tamhane's T2 post hoc test. $\mathrm{P}<0.05$ was considered to indicate a statistically significant difference.

\section{Results}

Construction of mice model with BLM-induced pulmonary fibrosis. To verify the BLM-induced model of pulmonary fibrosis in mice, a pulmonary CT scan and histopathological analysis were performed. The pulmonary CT scan revealed that the lung markings of the mice in the control group were regular, with no significant abnormality in the pulmonary parenchyma. However, the CT manifestations in BLM at 14 days were as follows: Increased bronchovascular shadows; patch lesions; diffuse dot-like patchy shadows; inhomogeneous high-density areas; blurred margins; and involvement of both lungs primarily in the lower field of the lungs (Fig. 1A). H\&E staining demonstrated complete alveolar structure, normal alveolar septum as well as no evident inflammatory infiltration in lungs from mice of control group (Fig. 1B). In the BLM model, the alveolar septum was widened, the alveolar wall was collapsed or disappeared, and interstitial infiltration was evident with a large number of inflammatory cells. In addition, Masson's trichrome staining revealed that the density of collagen fibers in the alveolar epithelium and bronchial area was markedly increased in the BLM group compared with the control group (Fig. 1B). Histological analysis revealed BLM-induced architecture destruction and collagen deposition in lungs from mice, suggesting that the mice model of pulmonary fibrosis was constructed successfully.

Expression of LOXL2 in mice of BLM-induced pulmonary fibrosis. As LOXL2 is essential in mediating collagen crosslinking and deposition (13), whether LOXL2 is involved in BLM-induced lung fibrosis was investigated. First, LOXL2 expression in serum, lung homogenate and pulmonary tissues in mice of BLM-induced pulmonary fibrosis was detected by ELISA and immunohistochemical analysis. As expected, BLM significantly induced LOXL2 expression in the serum and lung homogenate of mice compared with the control group (Fig. 2A). In addition, immunohistochemical analysis revealed that LOXL2 expression was low in the alveolar epithelial cells and partial macrophage cytoplasm in lung tissues of the control group, while in the BLM group, evident expression of LOXL2 was observed in certain alveolar epithelial cells in areas of severe lesions (Fig. 2B). Thus, LOXL2 may be associated with BLM-induced pulmonary fibrosis.

Transfection efficiency and silencing effect of LOXL2 siRNA adenovirus vectors on MLFs. To further investigate the specific role of LOXL2 in BLM-induced experimental lung fibrosis, LOXL2 silencing was performed on MLFs from mice with pulmonary fibrosis by administration of adenovirus-based LOXL2 siRNA. Following BLM modeling for 14 days, primary MLFs from the lung tissue in the BLM and control groups were isolated and cultured to form a stable cell line. Cell morphology analysis revealed primary long spindles, polygonal in shape. Immunofluorescence analysis indicated that red fluorescence protein-labeled $\alpha$-SMA was extensively expressed in the cytoplasm of primary fibroblasts, conforming to the characteristics of fibroblasts (Fig. 3A). The results of gene sequencing from the primary fibroblasts were consistent with the two sequences of LOXL2 siRNA and the control siRNA sequence designed in the present study, thus indicating that they were stably expressed (Fig. 3B-D). Flow cytometry demonstrated that the transfection efficiency of LOXL2 siRNA in MLFs was $>70 \%$ (Fig. 3E). RT-qPCR demonstrated that LOXL2 mRNA and protein levels in the BLM group were significantly higher compared with that in the control group (Fig. 3F). In addition, the expression of LOXL2 was significantly decreased in the BLM group following the knockdown with the two siRNAs compared with the BLM only and BLM+siControl groups, and there were no difference between the BLM only and BLM+siControl groups. The two siRNAs exhibited a marked silencing effect on LOXL2 expression; both decreased LOXL2 expression by $>60 \%$ (Fig. 3F) following treatment with LOXL2 siRNA. Similar to findings with mRNA expression, LOXL2 siRNA transfection markedly decreased LOXL2 protein expression in MLFs compared with the BLM and control siRNA groups (Fig. 3G), indicating that the LOXL2 siRNA constructed in the present study efficiently transfected MLFs and silenced LOXL2.

Effects of LOXL2 siRNA on MLF proliferation and expression of fibrosis-associated factors. As MLFs rapidly proliferate and differentiate into myofibroblasts with the progression of fibrosis, the effect of LOXL2 siRNA on MLF proliferation was assessed. The proliferation rate of MLFs from mice with BLM-induced pulmonary fibrosis elevated significantly at 24, 48, 72 and $96 \mathrm{~h}$ compared with that of MLFs from the BLM control group $(\mathrm{P}<0.01$; Fig. 4A). Following LOXL2 siRNA infection, the proliferation of MLFs in the BLM group declined significantly, particularly after $48 \mathrm{~h}$, compared with the BLM 
A
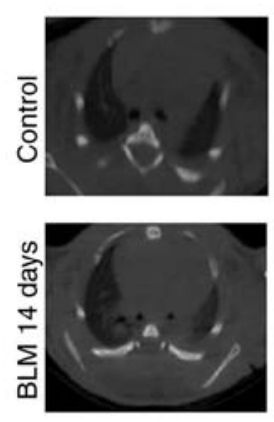
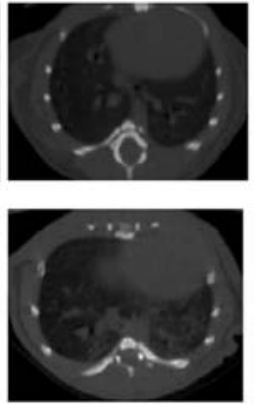

B
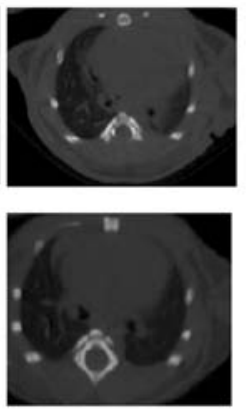

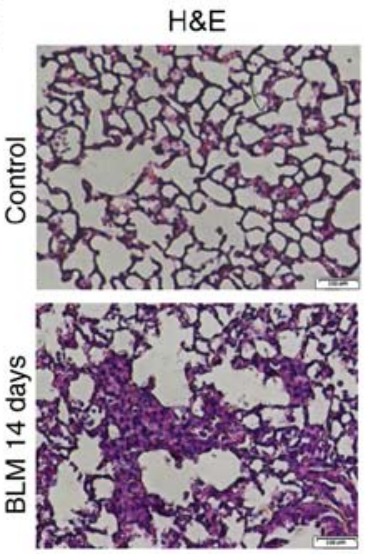

Masson



Figure 1. Computed tomography and histopathological changes associated with BLM-induced pulmonary fibrosis in mice. (A) Aortic arch level, diaphragm level and bronchial bifurcation level were selected as representative levels of lung computed tomography image acquisition. (B) Pathological changes were detected by H\&E and Masson's trichrome staining. H\&E staining was used to evaluate the infiltration and structure of lung tissue, and Masson's staining was used to observe the degree of fibrosis. Scale bar, $100 \mu \mathrm{m}$. H\&E, hematoxylin and eosin; BLM, bleomycin.

A

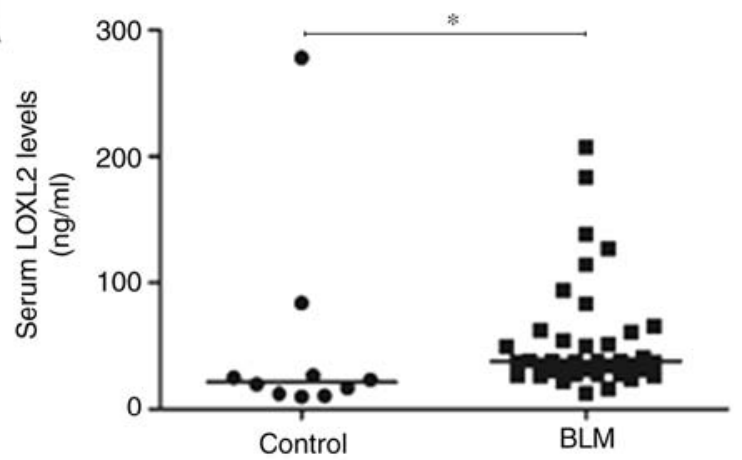

B

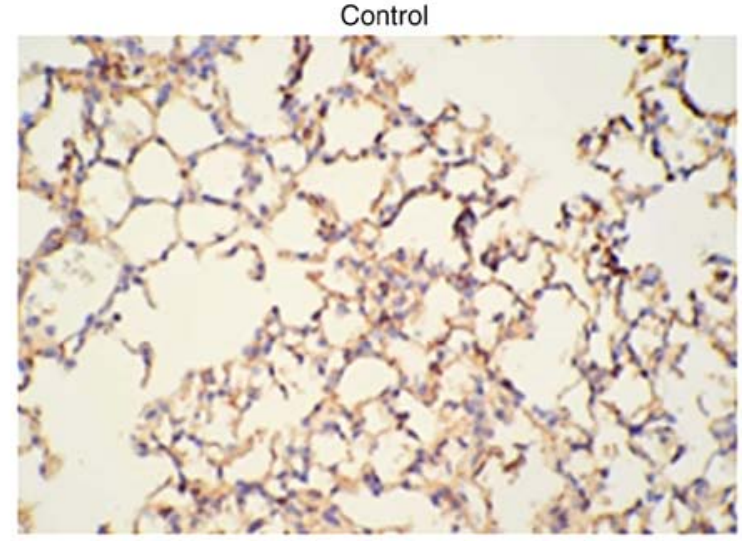

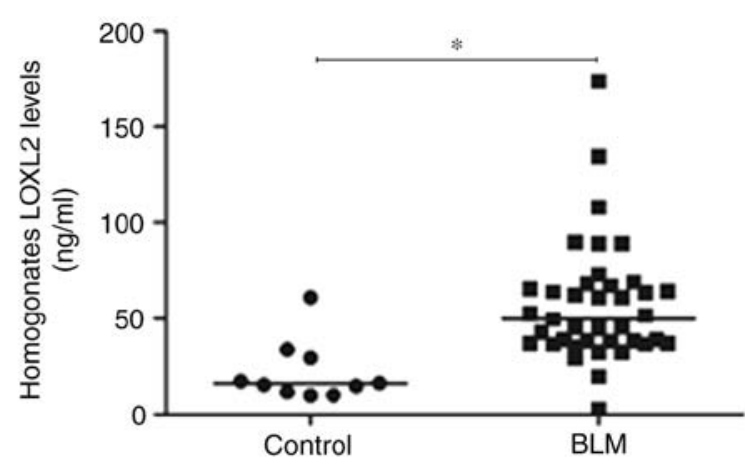

BLM

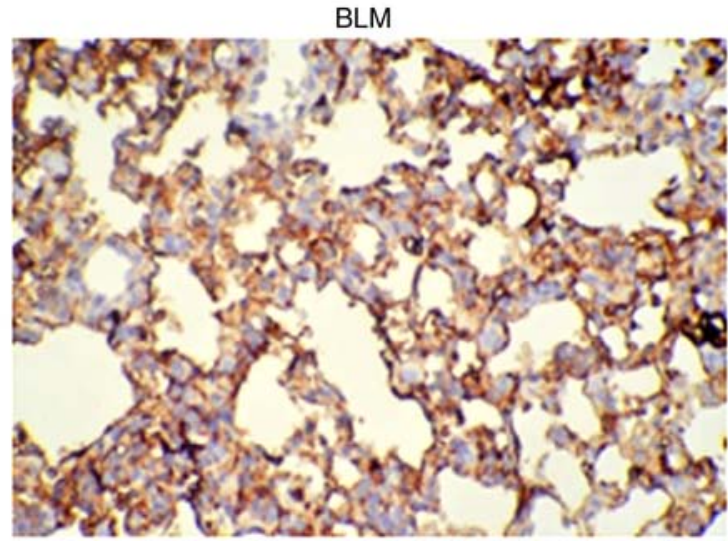

Figure 2. Expression of LOXL2 in serum and lung tissues of BLM-induced pulmonary fibrosis in mice. (A) Expression of LOXL2 in serum and lung homogenate was detected using ELISA. C57BL/6 wild-type mice, aged 7-8 weeks were used as the control group. *P<0.05. (B) LOXL2 expression intensity in lung tissue was assessed by immunohistochemical detection (magnification, x200). BLM, bleomycin; LOXL2, Lysyl oxidase-like 2.

only and control siRNA groups (both $\mathrm{P}<0.01$; Fig. $4 \mathrm{~A}$ ). In addition, the effects of LOXL2 siRNA on the expression of inflammatory factors IL-6 and extracellular matrix COL1A1 involved in fibrosis progression were observed. IL-6 and COL1A1 in the MLF supernatant from the BLM group were upregulated significantly compared with MLFs from the control group $(\mathrm{P}<0.01$ and $\mathrm{P}<0.05$, respectively; Fig. 4B and $\mathrm{C})$. Furthermore, LOXL2 siRNA significantly inhibited the expression of IL- 6 and COL1A1 in the MLF supernatant from mice with BLM-induced pulmonary fibrosis compared with the BLM only and BLM+siControl groups (both $\mathrm{P}<0.01$; Fig. 4B and C), suggesting that LOXL2 serves an essential role in fibrosis progression via MLFs in BLM-induced pulmonary fibrosis.

Effects of LOXL2 siRNA on the expression of key factors in the $T G F-\beta / S m a d$ signaling pathway. The aforementioned results represent an association between LOXL2 and BLM-induced pulmonary fibrosis, thus LOXL2 required further investigation as a potential biomarker for pulmonary fibrosis. The effect 

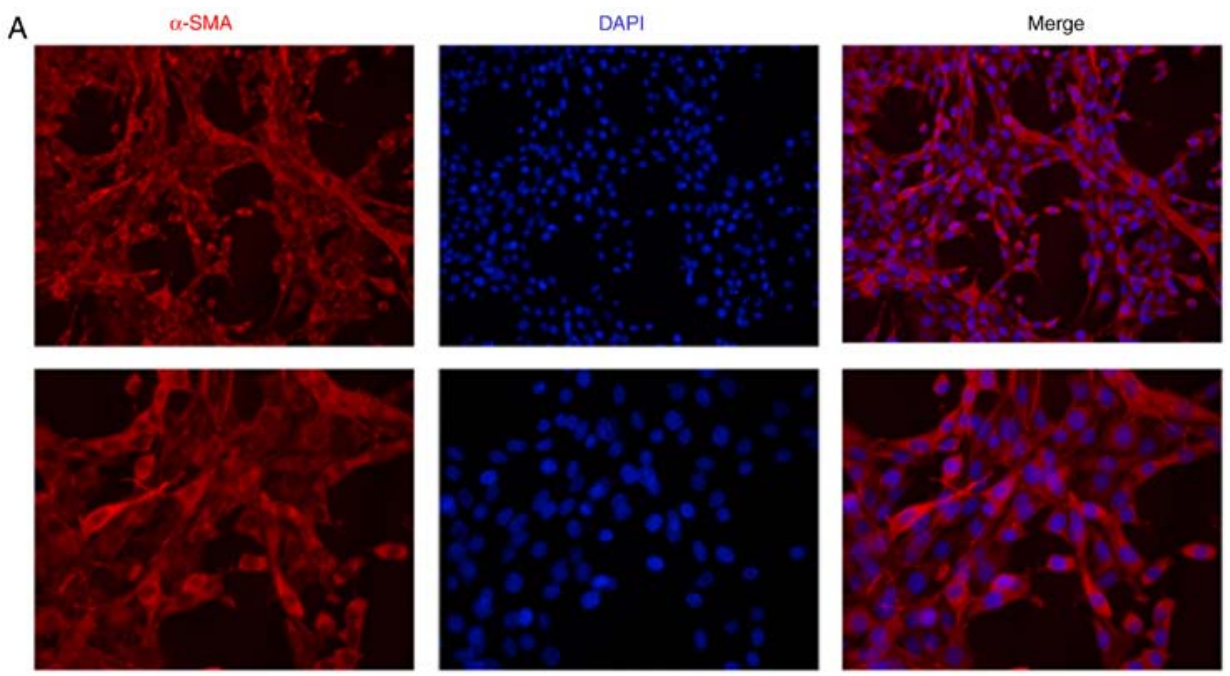

B LOXL2 SIRNA1

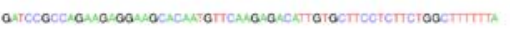

C LOXL2 SIRNA2
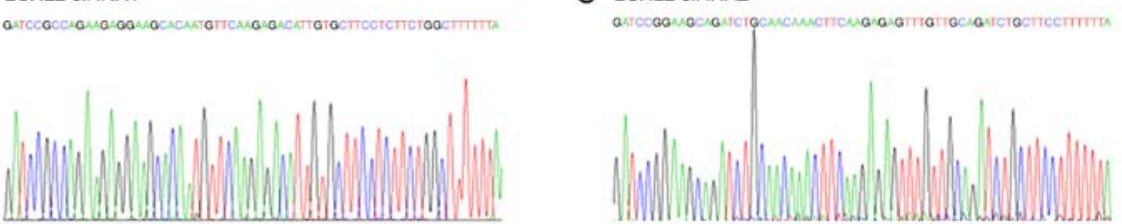

D

\section{Control siRNA}

GATCCGGTACTGGCATGGMAATCTTTCAMGGMGATATTTCCATGCCAGTACCTITITTA

E


$\mathrm{F}$

LOXL2



G

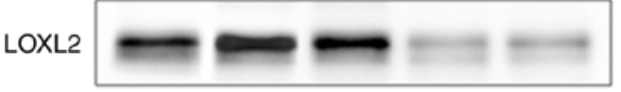

GAPDH

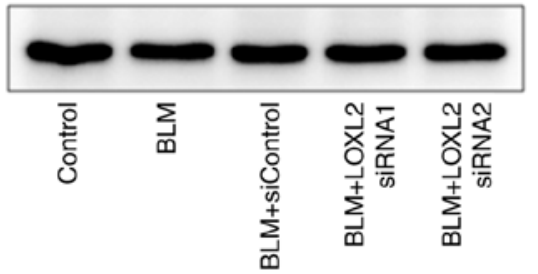

Figure 3. Identification of primary MLFs and transfection with LOXL2 siRNA. (A) Primary MLFs were identified by $\alpha$-SMA immunofluorescence. The nuclei were stained blue with DAPI. Red represents $\alpha$-SMA (magnifications, x200 and x400). Gene sequencing was used to identify the (B) LOXL2 siRNA1, (C) LOXL2 siRNA2 and (D) control siRNA. (E) Transfection efficiency of LOXL2 siRNAs and control siRNA in MLFs from mice with BLM-induced pulmonary fibrosis was assessed using flow cytometry. The silencing effect of LOXL2 siRNAs in MLFs detected using (F) reverse transcription-quantitative polymerase chain reaction and (G) western blotting. MLFs from C57BL/6 wild-type mice were used as the control group. "P<0.05 and ** $\mathrm{P}<0.01$. BLM, bleomycin; LOXL2, Lysyl oxidase-like 2; siRNA, small interfering RNA; MLFs, mouse lung fibroblasts; $\alpha$-SMA, $\alpha$-smooth muscle actin; GFP, green fluorescent protein. 


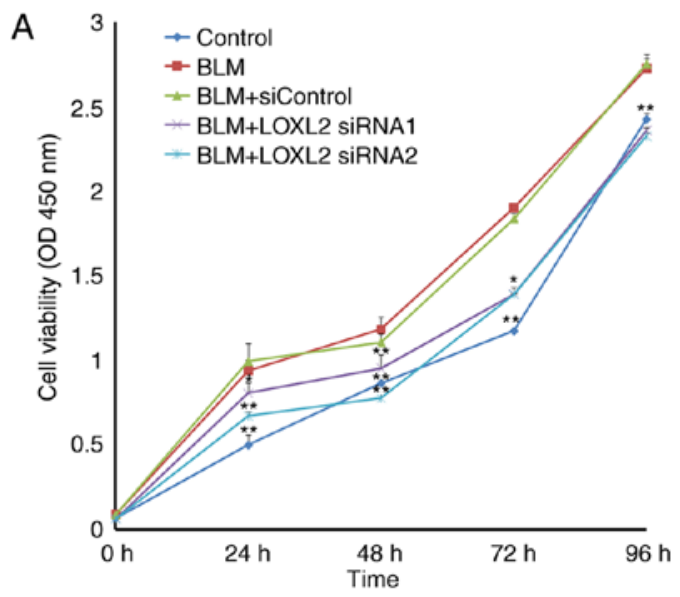

B
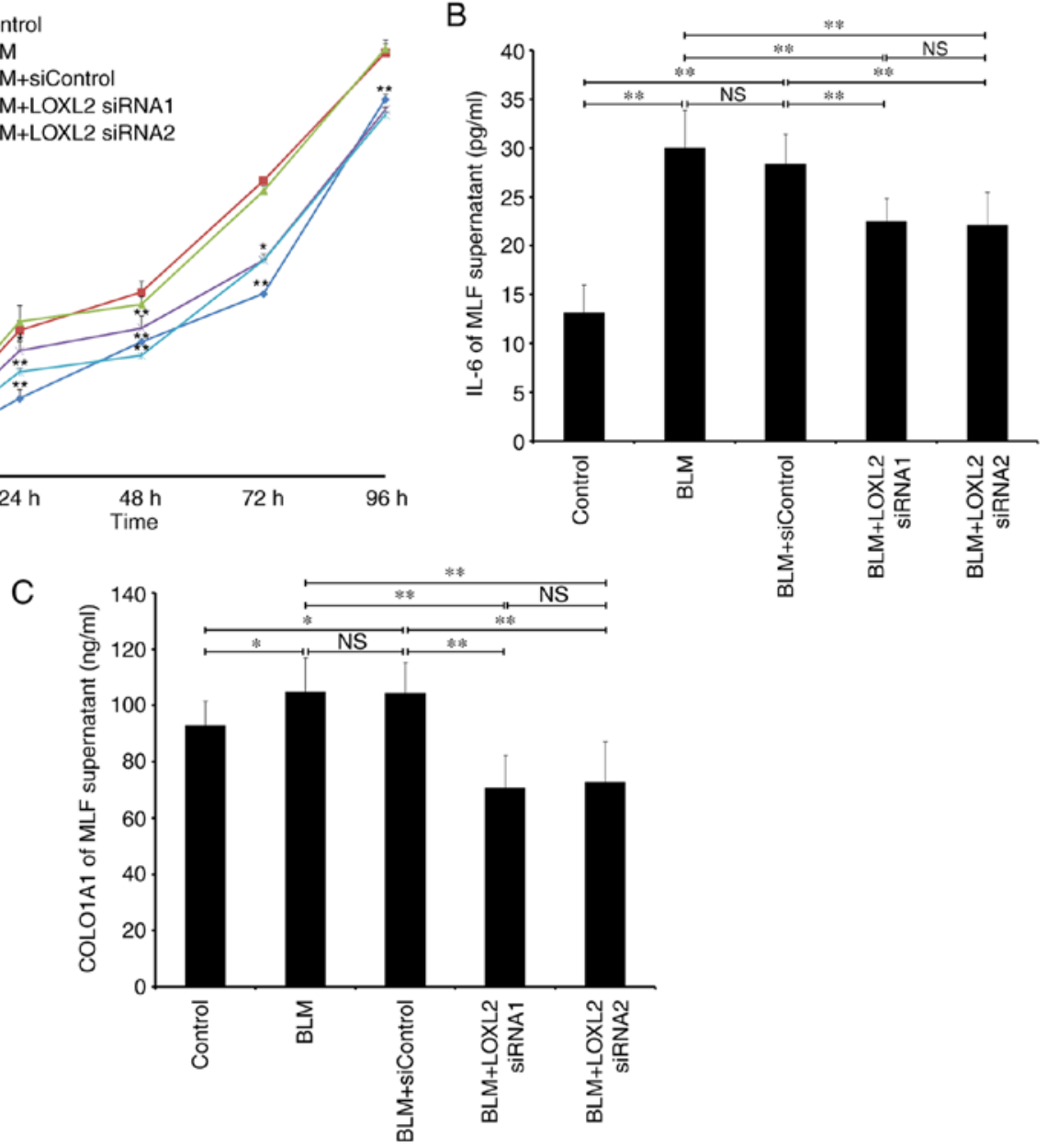

Figure 4. Proliferation rate and expression of fibrosis progression-associated factors in MLFs from mice with BLM-induced pulmonary fibrosis following LOXL2 siRNA transfection. (A) Cell proliferation levels of MLFs after 0, 24, 48, 72 and $96 \mathrm{~h}$ were assessed using cell counting kit-8 assay. Expression of (B) IL-6 and (C) COL1A1 in the supernatant of MLFs was detected using ELISA. MLFs from C57BL/6 wild-type mice were used as the control group. ${ }^{*} \mathrm{P}<0.05$ and ${ }^{* *} \mathrm{P}<0.01$. IL-6, interleukin-6; COL1A1, type 1 collagen $\alpha 1$; MLFs, mouse lung fibroblasts; siRNA, small interfering RNA; OD, optical density; BLM, bleomycin.

of LOXL2 siRNA on the TGF- $\beta$ signaling pathway in MLFs was assessed (Fig. 5). RT-qPCR demonstrated that MLFs from mice with BLM-induced pulmonary fibrosis exhibited significant upregulation of TGF- $\beta 1$ and Snail mRNA $(\mathrm{P}<0.05$ and $\mathrm{P}<0.01$, respectively; Fig. 5A and F), whereas Smad7 mRNA was significantly downregulated compared with the control groups $(\mathrm{P}<0.01$; Fig. 5E). Following LOXL2 siRNA transfection, the difference in Smad4 mRNA expression between the LOXL2 siRNAs and BLM only groups was significant $(\mathrm{P}<0.01)$; however, only LOXL2 siRNA1 induced a significant difference compared with the BLM+siControl group, whereas LOXL2 siRNA2 did not induce a significant difference compared with the BLM+siControl group. $(\mathrm{P}<0.05$ and $\mathrm{P}>0.05$, respectively; Fig. 5D). Moreover, the mRNA expression levels of Snail were significantly decreased in the siRNAs groups compared with the BLM only and BLM+siControl groups (both $\mathrm{P}<0.01$; Fig. 5F), whereas Smad7 mRNA expression was significantly increased $(\mathrm{P}<0.01$; Fig. $5 \mathrm{E})$. In addition, LOXL2 siRNA had no significant effect on the mRNA expression of TGF- $\beta 1$ and Smad2/3 in MLFs from the BLM group compared with BLM only and BLM+siControl groups ( $\mathrm{P}>0.05$; Fig. 5A-C). Similar to the mRNA findings, MLFs from the BLM group demonstrated markedly elevated protein levels of TGF- $\beta 1, \mathrm{pSmad} 2 / 3$ and Snail compared with the MLFs from the control group. Following transfection with LOXL2 siRNA, the protein expression of $\mathrm{pSmad} 2 / 3, \mathrm{Smad} 4$ and Snail in the MLFs decreased markedly compared with the BLM only and control siRNA groups, while the expression of Smad7 increased (Fig. 5G). However, no marked reduction was observed in the protein expression of Smad2/3. Together, these data suggest that LOXL2 siRNA regulated the expression of key factors in the TGF- $\beta$ /Smad signaling pathway.

\section{Discussion}

Collagen matrix deposition and interstitial transition of epithelial cells are the primary features of pulmonary fibrosis occurrence and development. The LOX family is involved in the production of collagen matrix, regulation of extracellular matrix deposition and transition of epithelial cells to stroma cells (23). LOXL2 has been proposed to be structurally and functionally similar to LOX, which has been associated with disease-associated fibrogenesis by promoting the cross-linking of elastin and collagen fibers (24,25). Barker et al (26) demonstrated that LOXL2 mediated the crosslinking of the extracellular matrix to promote the activation of fibroblasts and large-scale production of $\alpha$-SMA. Chien et al (24) reported that serum levels of LOXL2 in patients with idiopathic pulmonary 
A

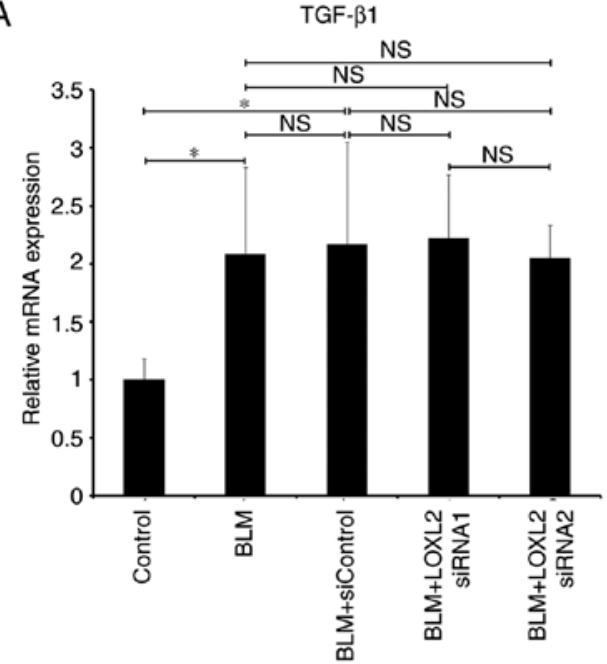

C

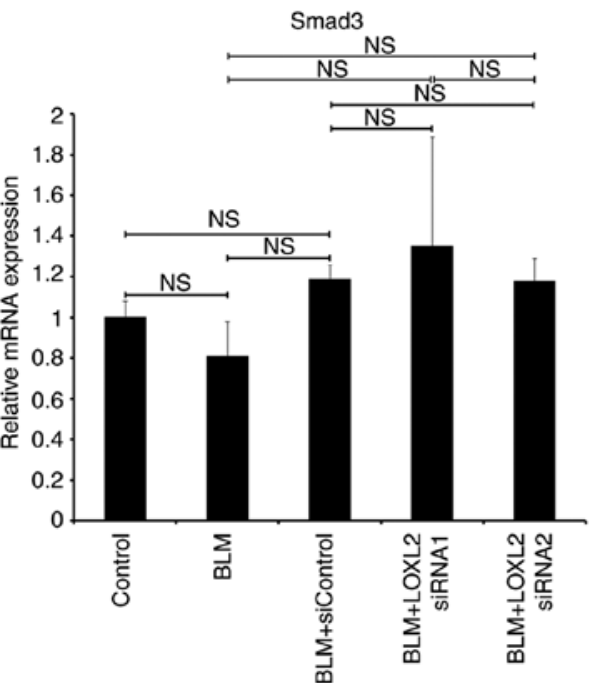

B

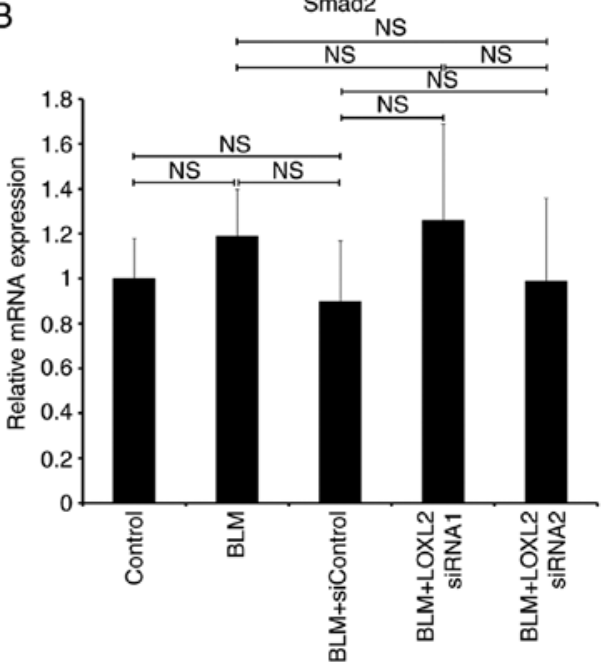

D

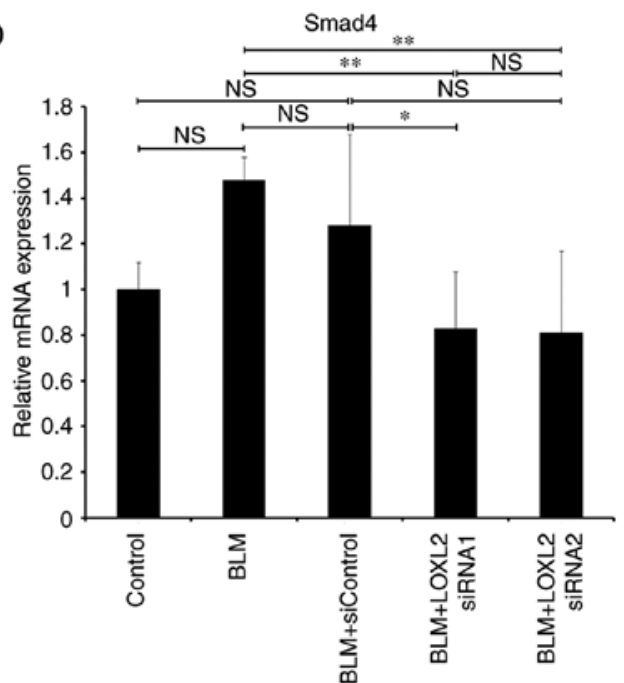

E



F

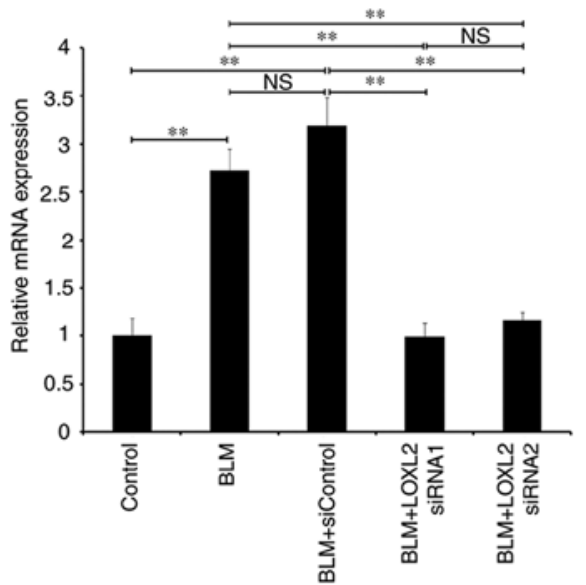

$\mathrm{G}$

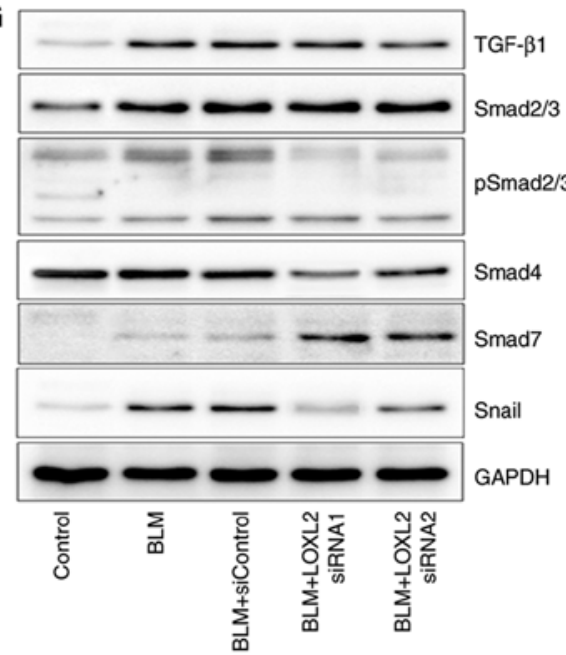

Figure 5. Expression of key factors of TGF- $\beta /$ Smad pathway in MLFs from mice with BLM-induced pulmonary fibrosis following LOXL2 siRNA transfection. The mRNA expression of (A) TGF- $\beta 1$, (B) Smad2, (C) Smad3, (D) Smad4, (E) Smad7 and (F) Snail was detected using reverse transcription-quantitative polymerase chain reaction and normalized to the expression of GADPH mRNA. (G) Expression of TGF- $\beta 1$, Smad2/3, pSmad2/3, Smad4, Smad7 and Snail proteins was detected using western blotting. Protein expression was normalized to the expression of $\beta$-actin. MLFs from C57BL/6 wild-type mice were used as the control group. " $\mathrm{P}<0.05$ and ${ }^{* *} \mathrm{P}<0.01$. LOXL2, Lysyl oxidase-like 2; TGF- $\beta 1$, tumor growth factor- $\beta$; siRNA, small interfering RNA; MLFs, mouse lung fibroblasts; BLM, bleomycin.

fibrosis were associated with the progression of the disease. In addition, it has been reported that inhibition of LOXL2 with an inhibitory monoclonal antibody is efficacious at fibrosis inhibition in murine models of fibrotic disease, including lung 
fibrosis and liver fibrosis (14). However, the exact effects of LOXL2 on the pathogenesis of pulmonary fibrosis, particularly its association with pulmonary fibrosis-associated signaling pathways, require further investigation.

Consistent with the aforementioned findings, substantial elevation of LOXL2 was observed in the serum and lung homogenate of mice with BLM-induced pulmonary fibrosis. Furthermore, the immunohistochemical analysis revealed BLM induced LOXL2 expression in pulmonary tissues (alveolar wall and interstitium) and the lesion area. Notably, Choi et al (27) revealed that LOXL2 was present in the fibrous interstitium and infiltrating mononuclear cells in a mouse model of tubulointerstitial fibrosis, demonstrating one possible mechanism that inflammatory milieu of LOXL 2 contributes to fibrosis progression. However, the immunohistochemical results of the present study did not observe evident LOXL2 expression in inflammatory cells. In combination with the current understanding of the role of LOXL2 in pulmonary fibrosis, these findings suggest that LOXL2 may be associated with BLM-induced pulmonary fibrosis. Next, LOXL2 was silenced using siRNA transfection in MLFs from mice with BLM-induced pulmonary fibrosis in order to further investigate the involvement of LOXL2 in pulmonary fibrosis. This enabled the in vitro observation of the effects of LOXL2 on the pathogenesis and progression of pulmonary fibrosis through the proliferation of MLFs, and the expression of factors involving in fibrosis progression in cells. In addition, the effects of LOXL2 silencing on the expression of key factors in the TGF- $\beta$ /Smad signaling pathway in MLFs were observed, and relevant mechanisms were further investigated.

Following the observation of high levels of LOXL2 in murine models of pulmonary fibrosis, whether LOXL2 is able to facilitate fibroblast proliferation and activation, and hence serve a role in fibrosis progression was investigated. Fibroblast proliferation and their transition to myofibroblasts as well as the large amount of extracellular matrix produced by fibroblasts, are the primary characteristics for the occurrence of pulmonary fibrosis (28), and are implicated in the maintenance and reconstruction of extracellular matrix. Furthermore, pro-inflammatory factor IL-6 and extracellular matrix Col I of myofibroblasts are involved in the proliferation, transformation and stromal deposition of fibroblasts, which are associated with the development of pulmonary fibrosis $(29,30)$. Notably, it has been demonstrated that LOXL2 is widely expressed in fibroblasts and serves an important role in fibroblasts activation (26). In the present study, primary MLFs from mice in the control and BLM-induced pulmonary fibrosis groups were selectively cultured and identified using $\alpha$-SMA detection. Then, MLFs from mice models of pulmonary fibrosis were transfected with LOXL2 siRNA. The data demonstrated that LOXL2 silencing in MLFs from BLM-induced fibrosis exhibited a significant inhibitory effect on MLF proliferation as well as the expression of IL-6 and COL1A1 compared with MLFs from the BLM group. These results support our previous finding that LOXL2 is involved in fibrosis progression, contributing to the fibrotic lung diseases.

In addition, whether LOXL2 acted synergistically with the TGF- $\beta$ /Smad signaling pathway was assessed in order to investigate the underlying mechanism. The classical TGF- $\beta 1 / \mathrm{Smad}$ signaling pathway is one of the signaling pathways involved in the occurrence of pulmonary fibrosis (17). TGF- $\beta 1$ acts on the target cells through the transmembrane receptor, thus leading to the phosphorylation of Smad2 and Smad3. Subsequently, phosphorylated $\mathrm{Smad} 2 / 3$ binds to Smad4 and enters the nucleus to form a Smad protein compound that interacts with the transcription factor Snail, regulating the transcription of fibrosis-associated genes downstream; however, the activation of this pathway is inhibited by Smad7 (17-19). Whether LOXL2 is the upstream molecule of the TGF- $\beta 1 / \mathrm{Smad}$ signaling pathway remains controversial. A previous study revealed that the expression of LOXL2 was significantly increased following the stimulation of airway epithelial cells by TGF- $\beta$ (15). Silencing LOXL2 completely abrogated the inhibitory effects of corilagin on TGF- $\beta 1$-induced epithelial-mesenchymal transition in A549 cells (21). However, another study reported that LOXL2 inhibition impaired fibroblast activation in in vivo models of fibrosis, and led to reductions in TGF- $\beta$ signaling (14). In addition, Millanes-Romero et al (13) demonstrated that LOXL2 affected the transcription of Snail, subsequently inducing the transition of epithelial cells to stromal cells. Peinado et al (31) revealed that LOXL2 downregulated the expression of E-cadherin in coordination with transcription factor Snail to promote the epithelial-mesenchymal transition. The aforementioned studies suggested that LOXL2 is associated with the TGF- $\beta 1 /$ Smad signaling pathway. In the present study, the gene and protein expression of the aforementioned factors in the TGF- $\beta 1 /$ Smad signaling pathway were detected, and the effects of LOXL2 on these factors were observed. The results indicated that silencing LOXL2 in MLFs from mice with BLM-induced fibrosis inhibited the gene and protein expression of Smad4 and Snail, as well as the protein expression of $\mathrm{pSmad} 2 / 3$, thereby upregulating the expression of inhibitory factor Smad7. However, no significant effects were observed on the expression of TGF- $\beta 1$ and Smad2/3. These results suggested that LOXL2 regulated Smad2/3 phosphorylation, and the expression of Smad4 and Snail in the TGF- $\beta 1$ signaling pathway, subsequently causing an effect on the expression of inhibitory factor Smad7. However, LOXL2 did not regulate the expression of TGF- $\beta$, suggesting that LOXL2 may be located downstream of TGF- $\beta$ or that they interact indirectly. Furthermore, the results of the present study demonstrated that silencing LOXL2 did not affect the expression of $\mathrm{Smad} 2 / 3$, while it affected its phosphorylation level, indicating that $\mathrm{Smad} / 3$ phosphorylation rather than its own expression was a key factor in the pathogenesis of fibrosis. These data revealed an association between LOXL2 and the TGF- $\beta /$ Smad signaling pathway in fibrotic progression.

The current study demonstrated that the expression of LOXL2 in serum and pulmonary tissues of mice with BLM-induced pulmonary fibrosis were significantly elevated compared with control mice. MLFs from mice with BLM-induced pulmonary fibrosis were used in subsequent experiments. LOXL2 siRNA inhibited the proliferation of MLFs in BLM-induced fibrosis and regulated the expression of important factors, including pSmad2/3, Smad4, Smad7 and Snail in the TGF- $\beta /$ Smad signaling pathway, suggesting that LOXL2 was involved in the fibrosis progression through regulation of the TGF- $\beta /$ Smad signaling pathway. Furthermore, this study provided an experimental basis for an in-depth study of LOXL2 in the pathogenesis of pulmonary fibrosis and its 
potential as the therapeutic target. However, numerous questions remain to be addressed, including whether LOXL2 is involved in inflammation associated to BLM-induced fibrosis, how it interacts with TGF- $\beta 1$, whether TGF- $\beta 1$ regulates LOXL 2 or LOXL 2 regulates TGF- $\beta 1$, and what the underlying mechanism of LOXL2 is. In addition, the association between LOXL 2 and TGF- $\beta$ non-Smad signaling pathways requires further investigation.

In conclusion, the present study investigated the effects of LOXL2 expression in pulmonary fibrosis, and effect on the proliferation, activation and fibrosis process of MLFs. Furthermore, these results indicate a regulatory role for LOXL2 in fibrogenesis via the TGF- $\beta /$ Smad signaling pathway. Based on these findings, we hypothesize that LOXL2 participates in the pathogenesis of pulmonary fibrosis and may be a simultaneous therapeutic target.

\section{Acknowledgements}

Not applicable.

\section{Funding}

The project was supported by the National Natural Science Foundation of China (grant no. 81471616), the Research Funds of Baotou Medical College (grant no. BYJJ-YF 2016100) and the Natural Science Foundation of Inner Mongolia [grant no. 2017MS (LH)0812].

\section{Availability of data and materials}

The datasets used and/or analyzed during the current study are available from the corresponding author on reasonable request.

\section{Authors' contributions}

YZ contributed to experimental design, coordination and revised drafts of the manuscript. XW performed animal experiment, analyzed and interpreted the data. YL performed the cell experiments, analyzed the results and drafted the manuscript. YB and ML performed the histological examinations and ELISA analysis. QF participated in construction of LOXL2 siRNA and cell culture. All authors read and approved the final manuscript.

\section{Ethics approval and consent to participate}

Animals experiments involving included studies have been approved by the Experimental Animal Welfare Committee of Capital Medical University (approval no. AEEI-2018-068) in compliance with applied principles of experimental animals.

\section{Patient consent for publication}

Not applicable.

\section{Competing interests}

The authors have declared that they have no competing interests.

\section{References}

1. Churg A, Muller NL and Wright JL: Respiratory bronchiolitis/interstitial lung disease: Fibrosis, pulmonary function, and evolving concepts. Arch Pathol Lab Med 134: 27-32, 2010.

2. Yoshida M, Sakuma J, Hayashi S, Abe K, Saito I, Harada S, Sakatani M, Yamamoto S, Matsumoto N, Kaneda Y, et al: A histologically distinctive interstitial pneumonia induced by overexpression of the interleukin 6 , transforming growth factor beta 1, or platelet-derived growth factor B gene. Proc Natl Acad Sci USA 92: 9570-9574, 1995.

3. Gross TJ and Hunninghake GW: Idiopathic pulmonary fibrosis. N Engl J Med 345: 517-525, 2001.

4. Todd NW, Luzina IG and Atamas SP: Molecular and cellular mechanisms of pulmonary fibrosis. Fibrogenesis Tissue Repair 5: 11, 2012.

5. Kurundkar A and Thannickal VJ: Redox mechanisms in age-related lung fibrosis. Redox Biol 9: 67-76, 2016.

6. Lederer DJ and Martinez FJ: Idiopathic pulmonary fibrosis. N Engl J Med 378: 1811-1823, 2018.

7. Bagnato G and Harari S: Cellular interactions in the pathogenesis of interstitial lung diseases. Eur Respir Rev 24: 102-114, 2015.

8. Raghu G, Collard HR, Egan JJ, Martinez FJ, Behr J, Brown KK, Colby TV, Cordier JF, Flaherty KR, Lasky JA, et al: An official ATS/ERS/JRS/ALAT statement: Idiopathic pulmonary fibrosis: Evidence-based guidelines for diagnosis and management. Am J RespirCrit Care Med 183: 788-824, 2011.

9. GBD 2013 Mortality and Causes of Death Collaborators: Global, regional, and national age-sex specific all-cause and cause-specific mortality for 240 causes of death, 1990-2013: A systematic analysis for the Global Burden of Disease Study 2013. Lancet 385: $117-171,2015$

10. Lucero HA and Kagan HM: Lysyl oxidase: An oxidative enzyme and effector of cell function. Cell Mol Life Sci 63: 2304-2316, 2006.

11. Kagan HM and Li W: Lysyl oxidase: Properties, specificity, and biological roles inside and outside of the cell. J Cell Biochem 88: 660-672, 2003

12. Magdaleno F and Trebicka J: Selective LOXL2 inhibition: Potent antifibrotic effects in ongoing fibrosis and fibrosis regression. Gut 66: 1540-1541, 2017.

13. Millanes-Romero A, Herranz N, Perrera V, Iturbide A, LoubatCasanovas J, Gil J, Jenuwein T, García de Herreros A and Peiró S: Regulation of heterochromatin transcription by Snail1/LOXL2 during epithelial-to-mesenchymal transition. Mol Cell 52: 746-757, 2013.

14. Barry-Hamilton V, Spangler R, Marshall D, McCauley S, Rodriguez HM, Oyasu M, Mikels A, Vaysberg M, Ghermazien H, Wai C, et al: Allosteric inhibition of lysyl oxidase-like-2 impedes the development of a pathologic microenvironment. Nat Med 16: 1009-1017, 2010

15. Aumiller V, Strobel B, Romeike M, Schuler M, Stierstorfer BE and Kreuz S: Comparative analysis of lysyl oxidase (like) family members in pulmonary fibrosis. Sci Rep 7: 149, 2017.

16. Hinz B, Phan SH, Thannickal VJ, Galli A, Bochaton-Piallat ML and Gabbiani G: The myofibroblast: One function, multiple origins. Am J Pathol 170: 1807-1816, 2007.

17. Derynck $R$ and Zhang YE: Smad-dependent and Smad-independent pathways in TGF- $\beta$ family signalling. Nature 425: 577-584, 2003.

18. Lee CM, Park JW, Cho WK, Zhou Y, Han B, Yoon PO, Chae J, Elias JA and Lee CG: Modifiers of TGF- $\beta 1$ effector function as novel therapeutic targets of pulmonary fibrosis. Korean J Intern Med 29: 281-290, 2014.

19. Medici $D$, Potenta $S$ and Kalluri R: Transforming growth factor- $\beta 2$ promotes Snail-mediated endothelial-mesenchymal transition through convergence of Smad-dependent and Smad-independent signalling. Biochem J 437: 515-520, 2011.

20. Cheng T, Liu Q, Zhang R, Zhang Y, Chen J, Yu R and Ge G: Lysyl oxidase promotes bleomycin-induced lung fibrosis through modulating inflammation. J Mol Cell Biol 6: 506-515, 2014.

21. Wei Y, Kim TJ, Peng DH, Duan D, Gibbons DL, Yamauchi M, Jackson JR, Le Saux CJ, Calhoun C, Peters J, et al: Fibroblast-specific inhibition of TGF- $\beta 1$ signaling attenuates lung and tumor fibrosis. J Clin Invest 127: 3675-3688, 2017.

22. Livak KJ and Schmittgen TD: Analysis of relative gene expression data using real-time quantitative PCR and the 2(-Delta Delta $\mathrm{C}(\mathrm{T})$ ) method. Methods 25: 402-408, 2001. 
23. Mäki JM, Sormunen R, Lippo S, Kaarteenaho-Wiik R, Soininen R and Myllyharju J: Lysyl oxidase is essential for normal development and function of the respiratory system and for the integrity of elastic and collagen fibers in various tissues. Am J Pathol 167: 927-936, 2005.

24. Chien JW, Richards TJ, Gibson KF, Zhang Y, Lindell KO, Shao L, Lyman SK, Adamkewicz JI, Smith V, Kaminski N and O'Riordan T: Serum lysyl oxidase-like 2 levels and idiopathic pulmonary fibrosis disease progression. Eur Respir J 43: 1430-1438, 2014.

25. Moon HJ, Finney J, Ronnebaum T and Mure M: Human lysyl oxidase-like 2. Bioorg Chem 57: 231-241, 2014.

26. Barker HE, Bird D, Lang G and Erler JT: Tumor-secreted LOXL2 activates fibroblasts through FAK signaling. Mol Cancer Res 11: 1425-1436, 2013.

27. Choi SE, Jeon N, Choi HY, Shin JI, Jeong HJ and Lim BJ: Lysyl oxidase-like 2 is expressed in kidney tissue and is associated with the progression of tubulointerstitial fibrosis. Mol Med Rep 16: $2477-2482,2017$.
28. Senavirathna LK, Huang C, Yang X, Munteanu MC, Sathiaseelan R, Xu D, Henke CA and Liu L: Hypoxia induces pulmonary fibroblast proliferation through NFAT signaling. Sci Rep 8: 2709, 2018.

29. Hansen NU, Karsdal MA, Brockbank S, Cruwys S, Rønnow S and Leeming DJ: Tissue turnover of collagen type I, III and elastin is elevated in the PCLS model of IPF and can be restored back to vehicle levels using a phosphodiesterase inhibitor. Respir Res 17: 76, 2016.

30. O'Reilly S, Ciechomska M, Cant R and van Laar JM: Interleukin-6 (IL-6) trans signaling drives a STAT3-dependent pathway that leads to hyperactive transforming growth factor- $\beta$ (TGF- $\beta$ ) signaling promoting SMAD3 activation and fibrosis via Gremlin protein. J BiolChem 289: 9952-9960, 2014.

31. Peinado H, Del Carmen Iglesias-de la Cruz M, Olmeda D, Csiszar K, Fong KS, Vega S, Nieto MA, Cano A and Portillo F: A molecular role for lysyl oxidase-like 2 enzyme in snail regulation and tumor progression. EMBO J 24: 3446-3458, 2005. 